www.jmscr.igmpublication.org

Index Copernicus Value: 79.54

ISSN (e)-2347-176x ISSN (p) 2455-0450

crossref DOI: https://dx.doi.org/10.18535/jmscr/v7i4.124

\title{
Radiological Study of Congenital Anomalies in Profoundly Deaf Children
}

\author{
Authors \\ Munjal VR ${ }^{1}$, Yadav $\mathbf{N}^{2}$, Mishra $A^{3}$ \\ ${ }^{1}$ Professor and Head, Department of Otorhinolaryngology, Head and Neck Surgery, Sri Aurobindo Medical \\ College and Post Graduate Institute, Indore (M.P.) \\ ${ }^{2,3}$ Junior Resident, Department of Otorhinolaryngology, Head and Neck Surgery, Sri Aurobindo Medical \\ College and Post Graduate Institute, Indore (M.P.)
}

\begin{abstract}
Introduction: Sensorineural hearing loss (SNHL) is a major cause of childhood disability worldwide, with an estimated prevalence of 1 in 2000 neonates and 6 in 1000 children by 18 years of age. Imaging plays an important role in the evaluation of congenital sensorineural hearing loss. It provides vital preoperative information about the Temporal bone and its anomalies, the vestibulocochlear nerve, and brain.

Aims \& Objective: To study and evaluate the causes of congenital sensorineural hearing loss through radiological screening (CT/MRI) with following objectives (a) To find the incidence of cochlear malformations, vestibular semicircular canal, Vestibular and cochlear aqueduct malformations and (b) To find the incidence of Cochlear nerve deficiency, endolymphatic duct, Internal auditory canal abnormality.

Methods: All patients with congenital sensorineural hearing loss who visited study center were included who fulfilled the selection criteria. A total of 150 congenital SNHL patients were selected from the Department of Otorhinolaryngology and head and neck surgery at Sri Aurobindo Medical College and Post Graduate Institute, Indore. All patients were subjected to audiological assessment, ear examination, CT and MRI temporal bone.

Results: In 150 patients we found 25 (17\%) patients had inner ear abnormality. Males were $72 \%$ and $28 \%$ were female, aged between 1 to 7 years.

Conclusion: Inner ear malformations were found in $17 \%$ of patients with congenital sensorineural hearing loss. High-resolution CT and MR imaging plays an important role in the evaluation of congenital hearing loss by providing crucial information about the inner ear, vestibulocochlear nerve, and brain.

Keywords: Congenital sensorineural hearing loss, inner ear abnormalities, computed tomography, magnetic resonance imaging.
\end{abstract}

\section{Introduction}

Sensorineural hearing loss (SNHL) is a multifaceted condition with profound medical and social effects. SNHL is a major cause of childhood disability worldwide, with an estimated prevalence of 1 in 2000 neonates and 6 in 1000 children by 18 years of age. ${ }^{[1]}$ Early diagnosis and treatment of SNHL in children is critical because it is well recognized that a delay in identification of hearing impairment can adversely affect speech and language development, academic achievement, and social and emotional development. ${ }^{[2]}$ Imaging plays an important role in the evaluation of congenital sensorineural hearing loss. 
It provides vital preoperative information about the Temporal bone and its anomalies, the vestibulocochlear nerve, and brain. In patients with congenital sensorineural hearing loss (SNHL) abnormalities of the inner ear that cannot be detected by conventional imaging techniques. High-resolution temporal bone computed tomography (CT) has been the first line imaging study of choice obtained by pediatric otolaryngologists in the workup of children with all types of SNHL, including symmetric, asymmetric, and unilateral SNHL. ${ }^{[3,4,5,6]}$

Adults with asymmetric or unilateral SNHL often undergo gadolinium- enhanced magnetic resonance(MR) imaging of the brain with attention to the internal auditory canals to evaluate for retrocochlear abnormalities. ${ }^{[7,8]}$ In contrast to adults, children with unilateral or asymmetric SNHL rarely have acoustic neuromas, and therefore the indications for MR imaging are less clear. $^{[8]}$

Congenital malformations of the inner ear are rare anomalies; they can be identified on imaging with HRCT and/or MRI in about $20 \%$ of patients with congenital sensorineural hearing loss. ${ }^{[9]}$ Bony abnormality of the inner ear can be detected in $10 \%-25 \%$ of such patients by conventional computed tomography (CT).

High-resolution computed tomography (CT) and magnetic resonance (MR) imaging provide excellent delineation of the intricate anatomy of the inner ear. Narrow internal auditory canal (IAC) with duplication is a rare congenital disorder that is usually associated with other inner ear, middle or external ear abnormalities. ${ }^{[10]} \mathrm{A}$ narrow IAC can be diagnosed when the diameter of IAC is less than $2 \mathrm{~mm}$ as seen on highresolution CT (HRCT) of the temporal bone. ${ }^{[11]}$ This malformation comprises $12 \%$ of congenital temporal bone anomalies. ${ }^{[9,12]}$ It has been thought that this anomaly is caused by aplasia or hypoplasia of the vestibulocochlear nerve that results in ipsilateral congenital sensorineural hearing loss. ${ }^{[10,11,13]} \mathrm{CT}$ depicts the minute details of osseous structures, and MR imaging allows visualization of the fluid-filled spaces and the vestibulocochlear nerve. Together, these complementary modalities can aid in decision making about the best management strategy by facilitating the identification and characterization of inner ear malformations and any associated neurologic abnormalities.

\section{Aim}

To study and evaluate the causes of congenital sensorineural hearing loss through radiological screening (CT/MRI).

\section{Objectives}

- To find the incidence of cochlear malformations.

- To find the incidence of vestibular malformations.

- To find the incidence of Malformations of semicircular canals.

- To find the incidence of Vestibular and cochlear aqueduct malformations.

- To find the incidence of Cochlear nerve deficiency.

- To find the incidence of endolymphatic duct abnormality.

- To find the incidence of Internal auditory canal abnormality.

- To find the incidence of Facial nerve abnormality.

\section{Material and Methods}

Research Design: Retrospective and prospective (observational study).

Place of Study: The study was conducted in the Department of Otorhinolaryngology and Head and Neck Surgery at Sri Aurobindo Medical College and Post Graduate Institute, Indore (M. P.).

Study Duration: The duration of study was two year i.e. from January 2014 to December 2015.

Sampling: All patients with congenital sensory neural hearing loss according to inclusionexclusion criterion were selected.

\section{Study Tools}

1. History 
2. Examination

3. Routine investigations

4. Audiometery

5. Computed tomography temporal bone

6. MRI temporal bone

\section{Inclusion Criteria}

1. Patient attending the ENT OPD at Sri Aurobindo Institute Of Medical Sciences, Indore with complaint of unable to hear and speak since childhood.

2. Patients of age group 1-7 years

3. Patients with severe to profound and profound sensorineural hearing loss [ $>90$ $\mathrm{db}]$

4. Patient whose parents were willing to provided their voluntary written informed consent for letting their child participate in the study

\section{Exclusion Criteria}

1. Patient with middle ear pathology

2. Patient with tympanic membrane perforation

3. Uncooperative patient

4. Patient with age more than 7 years

5. Patient whose parents were not willing to provided their voluntary written informed consent for letting their child participate in the study

\section{Methodology}

The patients who presented with sensorineural hearing loss, their parents were explained clearly about the study and their willingness to allow their child participate in the study was recorded in a consent form, voluntarily signed by them. All the study related procedures were conducted after obtaining the written voluntary informed consent. A total of 150 congenital SNHL patients were selected from the Department of Otorhinolaryngology and Head and Neck surgery at Sri Aurobindo Institute of Medical Sciences and Post Graduate Institute, Indore as patients for the study.

History recording and data collected when the analysis was performed. History in terms of antenatal, postnatal and birth history for infection, injury, immunization, consanguinity were collected. All the patients were subjected to audiological assessment, ear examination, CT and MRI of temporal bone. In all subjects complete general, systemic and ENT examination was done. Images were evaluated for presence of normal structure as well as for any anomaly. Present or absent of the nerves (facial, cochlear), relative internal auditory canal (IAC), and any associated inner ear abnormalities.

\section{Statistical Analysis}

Data were entered in Microsoft Excel and analysed using SPSS software. The data was calculated in the form of numbers and percentages. The final results were presented in the form of tables and graphs.

\section{Results}

In our study we had included 150 patients with congenital sensorineural hearing loss, of which were found abnormal findings in $25(17 \%)$ of the patients. There was a male preponderance in comparison to the females with a Male:Female ratio of $2.57: 1$.

Of the 25 abnormal patients, in $60 \%$ cochlear abnormalities were present, in $44 \%$ vestibular abnormality, semicircular canal and cochlear nerve abnormalities was present. In $48 \%$ vestibular aqueduct abnormalities [Fig. 1], in 32\% IAC abnormality, in $24 \%$ endolymphatic duct and in $8 \%$ facial nerve anomalies were present. [Table 1]

Of the $15(60 \%)$ cases of cochlear abnormalities, most of the patients $33 \%$ had cochlear hypoplasia, $13 \%$ had cochlear aplasia, 27\% had cochlear dysplasia, $20 \%$ had cystic cochlea and only $7 \%$ had cochlear dysplasia. [Fig. 2]

Of the 11 (44\%) patients with vestibular abnormalities, most of the patients had dilated vestibule i.e. $55 \%, 18 \%$ patients had common cavity, $9 \%$ patients had vestibule hypoplasia, cystic and absent vestibule. [Fig. 3]

$12(75 \%)$ patients had dilated vestibular aqueduct and $25 \%$ have absent vestibular aqueduct. 
Of $10(40 \%)$ patients with semicircularcanal abnormalities, $30 \%$ patients had PSCC abnormalities and only $10 \%$ cases had SCCC abnormalities.

Table 1: Distribution of patients according to abnormality

\begin{tabular}{|l|c|c|}
\hline \multicolumn{1}{|c|}{ Abnormality } & No of patients & Percentage \\
\hline Cochlear abnormality & 15 & $60 \%$ \\
\hline Vestibular abnormality & 11 & $44 \%$ \\
\hline Vestibular aqueduct & 12 & $48 \%$ \\
\hline Semicircular canal & 10 & $44 \%$ \\
\hline Cochlear nerve & 11 & $44 \%$ \\
\hline Facial nerve & 2 & $8 \%$ \\
\hline Endolymphatic duct & 6 & $24 \%$ \\
\hline Internal auditory canal & 8 & $32 \%$ \\
\hline
\end{tabular}

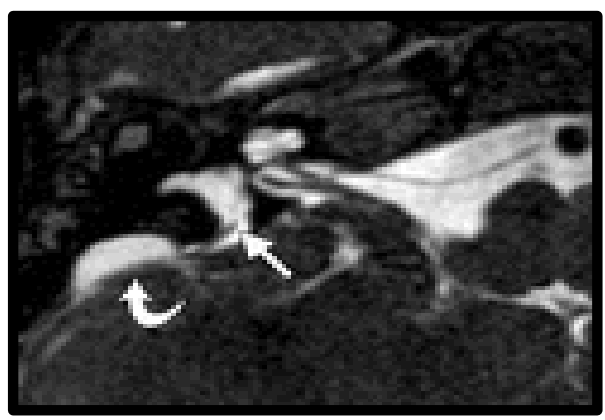

Fig. 1: Axial MR images show marked dilatation of the endolymphatic duct (straight arrow) and sac (curved arrow) in comparison with the normal posterior semicircular canal

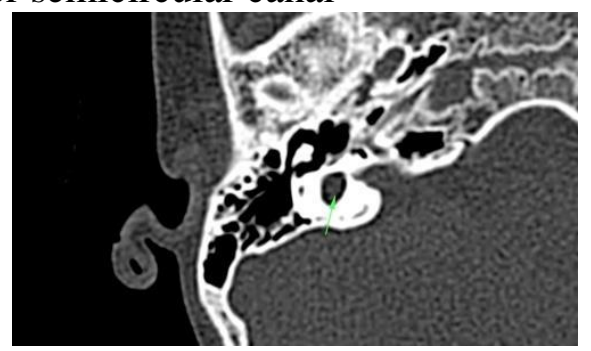

Fig. 2 : Common cavity of cochlea

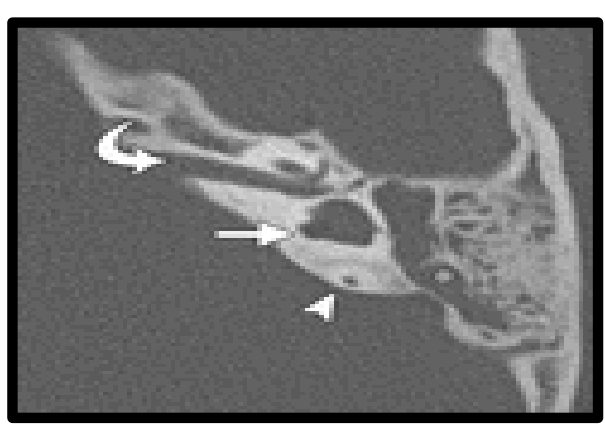

Fig. 3: Axial CT image shows a stenotic IAC (curved arrow), mildly dilated vestibule with a stunted lateral semicircular canal (straight arrow), and middle ear and mastoid air cell effusion. The posterior semicircular canal (arrowhead) appears normal.

\section{Discussion}

In our study, we found $25(17 \%)$ patients with inner ear abnormalities. While study done by Mafong et $\mathrm{al}^{[14]}$ found a higher percentage (39\%) and Huang et al ${ }^{[15]}$ found a very low percentage of inner ear abnormalities (9\%). While Dagkiran et $\mathrm{al}^{[16]}$ found an incidence similar to our study (20\%).

Male preponderance was seen in our study in comparison to females with a male:female ratio of 2.57 : 1. Similarly Halpin et al ${ }^{[17]}$ also found male preponderance.

We found $60 \%$ of the patients with cochlear abnormality on CT findings. Jackler et al found $76 \%$ cochlear abnormalities, while Reilly et al ${ }^{[18]}$ found only $4 \%$ abnormality in their study. Dagkiran et al ${ }^{[16]}$ found cochlear abnormalities in $13 \%$ of their series.

With regard to cochlear malformations, we found cochlear hypoplasia in $33 \%$ patients, cochlear aplasia in $13 \%$, cochlear dysplasia in $7 \%$, common cavity in $27 \%$ patients and cystic cavity in $20 \%$ patients. Jackler et al found common cavity in $26 \%$, cochlear aplasia in $1 \%$, cochlear hypoplasia in $15 \%$ and cystic cavity in $55 \%$ cases. Casselman et $\mathrm{al}^{[19]}$ found cochlear aplasia in $3 \%$ of their patients, Joshi et al ${ }^{[20]}$ found anomalies in $18 \%$ with most common as cochlear dysplasia in $10.2 \%$ patients.

Vestibular abnormality was seen in $44 \%$ patients, of which, dilated vestibule was the most common (55\%), followed by common cavity (18\%) and vestibule hypoplasia, cystic and absent vestibule in $9 \%$ patients. Joshi et $\mathrm{al}^{[20]}$ found vestibular dysplasia in $10.2 \%$ patients and $\mathrm{Wu}$ et $\mathrm{al}^{[15]}$ found $3 \%$ vestibular abnormalities.

$48 \%$ patients had vestibular aqueduct abnormality, of which, $75 \%$ patients had dilated vestibular aqueduct and $25 \%$ had absent vestibular aqueduct. Sennaroglu et $\mathrm{al}^{[21]}$ found VA in $22.2 \%$ in one study and $34 \%$ in another study.

Of the 25 cases of anomalies, $40 \%$ patients had semicircular canal abnormalities, of which $50 \%$ of patients had hypoplastic lateral semicircular canal, 
$33 \%$ patients had LSCC absent and $17 \%$ patients had dilated LSCC.

In the present study, 30\% patients had PSCC abnormalities and $10 \%$ patients had SCCC abnormalities. Joshi et $\mathrm{al}^{[19]}$ found semicircular canal dysplasia in $10.2 \%$ patients. Dagkiran et $\mathrm{al}^{[16]}$ found posterior semicircular canal malformation in $7.3 \%$ patients, lateral semicircular canal in $7.4 \%$ and superior semicircular canal aplasia / hypoplasia in 5.9\% patients.

Facial nerve abnormalities were seen in $8 \%$ of the patients and cochlear nerve abnormalities absence in $80 \%$ patients. Dagkiran et al ${ }^{[16]}$ found cochlear nerve absence in $15.4 \%$ patients.

$32 \%$ patients had internal auditory canal abnormality, of which $50 \%$ had narrow internal auditory canal and $37 \%$ patients had dilated internal auditory canal. Dagkiran et $\mathrm{al}^{[16]}$ found dilatation of internal acoustic canal in $30.9 \%$ patients.

Endolymphatic duct abnormalities were seen in $24 \%$ of the patients of the present study. Koesling et $\mathrm{al}^{[22]}$ found $10 \%$ patients with enlarged endolymphatic duct.

\section{Conclusion}

Inner ear malformations were found in $17 \%$ of patients with congenital sensorineural hearing loss. High-resolution CT and MR imaging play an important role in the evaluation of congenital hearing loss by providing crucial information about the inner ear, vestibulocochlear nerve, and brain. Both modalities precisely and accurately delineate the inner ear anatomy and malformations. They are often complementary and are used together in the preoperative evaluation of pediatric candidates for cochlear implantation. Most of the patients of congenital SNHL are found with cochlear malformations. Preoperative high-resolution CT offers the advantage of visualizing any coexistent middle or external ear anomalies and important anatomic variants, and MR imaging provides definitive information about the integrity of the cochlear nerve and the fluid-filled spaces of the inner ear. These radiological instruments aid in determining contraindications and predicting intraoperative difficulties. Identification of the inner ear abnormality has a substantial effect on clinical decision making, prognosis, and management strategy.

\section{References}

1. Billings KR, Kenna MA. Causes of pediatric sensorineural hearing loss: yesterday and today. Arch Otolaryngol Head Neck Surg 1999;125:517-21.

2. American Academy of Pediatrics, Joint Committee on Infant Hearing. Year 2007 position statement: principles and guidelines for early hearing detection and intervention programs. Pediatrics 2007;120:898-921.

3. Ohlms LA, Chen AY, Stewart MG, Franklin DJ. Establishing the etiology of childhood hearing loss. Otolaryngol Head Neck Surg. 1999 Feb;120(2):159-63.

4. Antonelli PJ, Varela AE, Mancuso AA. Diagnostic yield of high-resolution computed tomography for pediatric sensorineural hearing loss. Laryngoscope. 1999 Oct;109(10):1642-7.

5. Bamiou DE, Phelps P, Sirimanna T. Temporal bone computed tomography findings in bilateral sensorineural hearing loss. Arch Dis Child. 2000 Mar; 82(3):257-60.

6. Licameli GR, Robson C, Kenna MA. CT findings in children with unilateral sensori neural hearing loss.Poster presented at: 18th Annual Meeting of the American Society of Pediatric Otolaryngology; May 4-5, 2003; Nashville, Tenn.

7. Kumar A, Maudelonde C, Mafee M. Unilateral sensorineural hearing loss: analysis of 200 consecutive cases. Laryngoscope. 1986;96:14-8.

8. Shusterman D, Handler SD, Marsh RR. Usefulness of computed tomographics 
canin the evaluation of sensorineural hearing loss in children. Arch Otolaryngol Head Neck Surg. 1992;118:501-3.

9. Jackler RK, Luxford WM, House WF. Congenital malformations of the inner ear: A classification based on embryogenesis. Laryngoscope. 1987 Mar;97(3 Pt 2 Suppl 40):2-14.

10. Yates JA, Patel PC, Millman B, Gibson WB. Isolated congenital internal auditory canal atresia with normal facial nerve function. Int $\mathrm{J}$ Pediatr Otorhinolaryngol. 1997 Jul 18;41(1):1-8.

11. Ferreira T, Shayestehfar B, Lufkin R. Narrow, duplicated internal auditory canal. Neuroradiology. 2003 May;45(5):308-10.

12. Winslow CP, Lepore ML. Imaging quiz case 1. Bilateral agenesis of lateral semicircular canals with hypoplasia of the left internal auditory canal (IAC) Arch Otolaryngol Head Neck Surg. 1997;123:1236.

13. Cho YS, Na DG, Jung JY, et al. Narrow internal auditory canal syndrome :para saggital reconstruction. J Laryngol Otol. 2000;114:392-4.

14. Mafong DD, Shin EJ, Lalwani AK. Use of laboratory evaluation and radiologic imaging in the diagnostic evaluation of children with sensorineural hearing loss. Laryngoscope. 2002;112(1):1-7.

15. Wu WJ, He XB, Tan LH, Hu P, Peng AQ, Xiao ZA, et al. Imaging assessment of profound sensorineural deafness with inner ear anatomical abnormalities. Journal of Otology. 2015;10(1):29-38.

16. Dağkıran M1, Dağkıran N, Sürmelioğlu Ö, Ballı T, Tuncer Ü, Akgül E, Çetik F. Radiological Imaging Findings of Patients with Congenital Totally Hearing Loss. J Int Adv Otol. 2016 Apr;12(1):43-8.

17. Halpin C. Modern clinical methods in genetic hearing loss. Current Opinion in Otolaryngology \& Head and Neck Surgery. 1995;3(5):325-31.
18. Jackler R, Luxfor W, et al. Congenital malformations of the inner ear: A classification based on embryogenesis. The Laryngoscope. 2009;97(S40):2-14.

19. Casselman JW, Offeciers EF, De Foer B. CT and MR imaging of congential abnormalities of the inner ear and internal auditory canal. Eur J Radiol 2001;40(2): 94-104.

20. Joshi V, Navlekar S, et al. CT and MR Imaging of the Inner Ear and Brain in Children with Congenital Sensorineural Hearing Loss. RadioGraphics. 2012;32(3):683-698.

21. Sennaroğlu L, Saatçi I. Magnetic resonance imaging versus computed tomography in pre-operative evaluation of cochlear implant candidates with congenital hearing loss. J Laryngol Otol 2002; 116: 804-10.

22. Koesling S, Rasinski C, Amaya B et al. Imaging and clinical findings in large endolymphatic duct and sac syndrome. European Journal of Radiology. 2006;57(1):54-62. 